\title{
Contralateral Minimum Anterior and Posterior Combined Petrosal Approach for Retrochiasmatic Craniopharyngiomas: An Alternative Technique
}

\author{
Sachin Ranganatha Goudihalli ${ }^{1,3}$ Hiroki Morisako ${ }^{3}$ Wimba Prastarana ${ }^{2}$ Takeo Goto ${ }^{3}$ Hiroki Ohata ${ }^{3}$ \\ Kenji Ohata ${ }^{3}$ \\ ${ }^{1}$ Department of Neurosurgery, Fortis Hospital, Bangalore, India \\ ${ }^{2}$ Department of Neurosurgery, Airlangga University, Surabaya, \\ Indonesia \\ ${ }^{3}$ Department of Neurosurgery, Osaka City University Graduate \\ School of Medicine, Osaka, Japan

\begin{abstract}
Address for correspondence Kenji Ohata, MD, PhD, Department of Neurosurgery, Osaka City University Graduate School of Medicine, 1-4-3 Asahimachi, Abeno-ku, Osaka, 5458585, Japan

(e-mail: kohata@med.osaka-cu.ac.jp).
\end{abstract}

J Neurol Surg B 2018;79(suppl S2):S208-S210.

\begin{abstract}
\section{Keywords}

- retrochiasmatic craniopharyngioma

- petrosal approach

- interpeduncular fossa

- optic tract

Retrochiasmatic craniopharyngiomas (RC) are a challenge for the neurosurgeon to treat surgically, restrained by their location in the interpeduncular fossa, surrounded by vital neurovascular structures, narrow corridor and poor visibility. Many approaches are possible and elucidated in the literature, which the surgeon chooses, based on multiple factors, such as the size of tumor, calcification, laterality, preoperative neurological deficits and the endocrine function status, recurrence, postradiotherapy status, or significant superior and/or posterior extension. ${ }^{1,2}$

We describe a contralateral minimum anterior and posterior (CL-MAPC) petrosal approach for a case of recurrent RC, in a 37-year-old female patient operated before using a pterional approach, now presented with left homonymous hemianopia and panhypopituitarism (-Fig. 1). We preferred a contralateral approach to protect the ipsilateral optic tract (OT) from retraction injury, which formed an obstacle to the tumor from ipsilateral side. Apart from various benefits described by the author previously for RC, using MAPC petrosal approach, the CL-MAPC offers a safe corridor, protecting the ipsilateral OT, visualization of tumor origin usually posterior to chiasm,
\end{abstract}

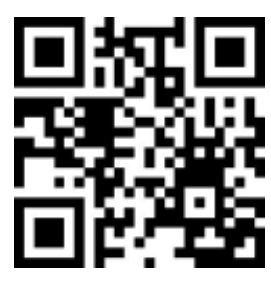

www.thieme.com/skullbasevideos

www.thieme.com/jnlsbvideos

received

October 27, 2017

accepted

October 29, 2017

published online

January 11, 2018
DOI https://doi.org/

10.1055/s-0037-1620248.

ISSN 2193-6331. (c) 2018 Georg Thieme Verlag KG

Stuttgart · New York
License terms

c) $(1) \$$ 
wider corridor if PCoM could be sacrificed, as it was done in this case, and pituitary stalk identification, with a probability of its functional preservation, unlike a necessity of pituitary transposition in EEA, though the endocrine outcome is poor after a radical resection irrespective of the approach chosen. ${ }^{1,3,4}$ There was complete excision of the tumor with preservation of visual function postoperatively. We recommend the use of CL-MAPC as an alternative to EEA in some specific indications when the tumor is large, calcified, obscuring OT on the ipsilateral side and with significant lateral extension, which may be limiting factors in EEA (-Fig. 2).

The link to the video can be found at: https://youtu.be/gWCJmh4_evs.

Conflict of Interest

None.

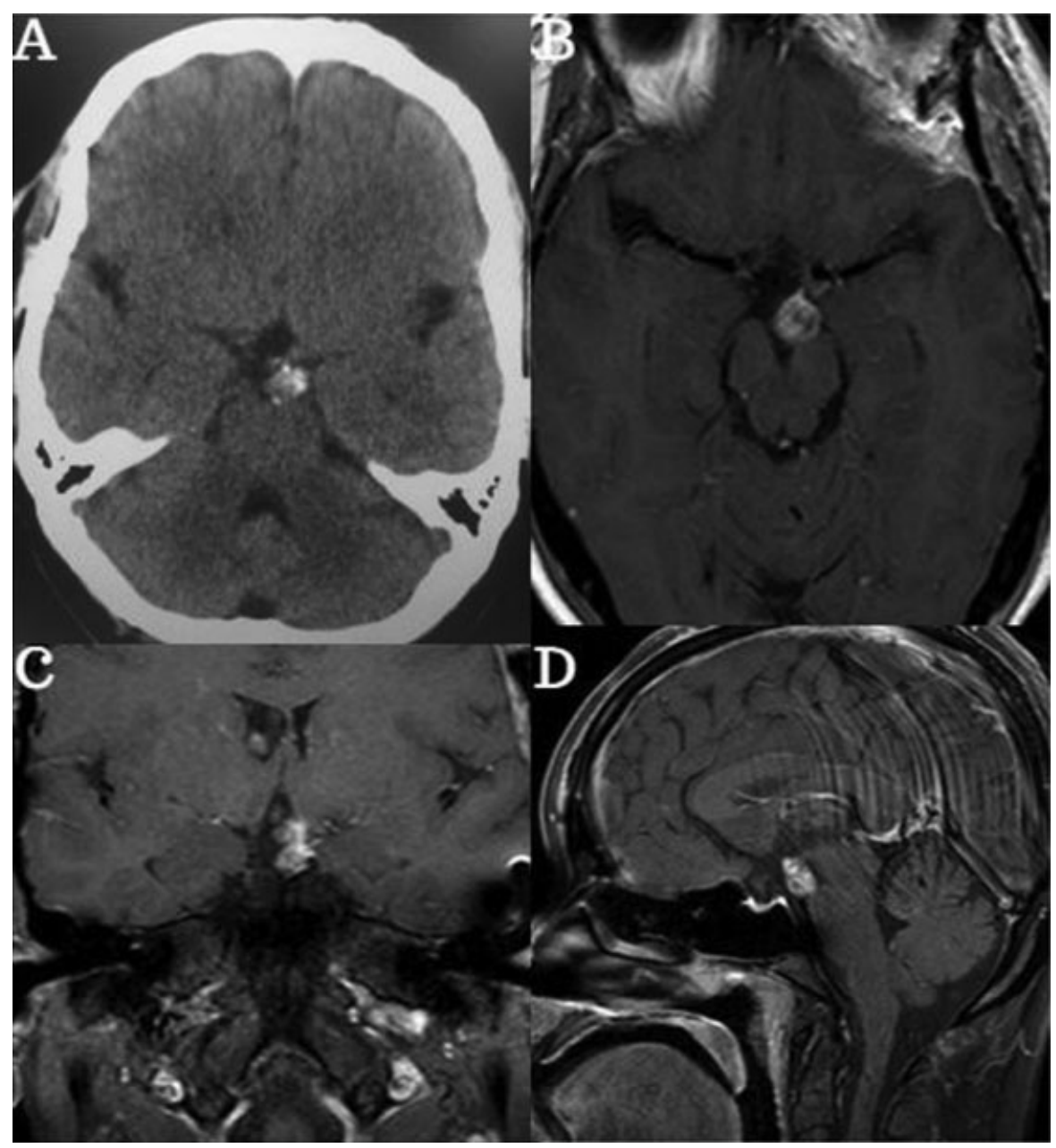

Fig. 1 Preoperative CT scan (A), and MRI including axial (B), coronal (C), and saggital (D) sequences showing tumor with calcification, in the retrochiasmatic area close to left optic tract. MRI, magnetic resonance imaging. 


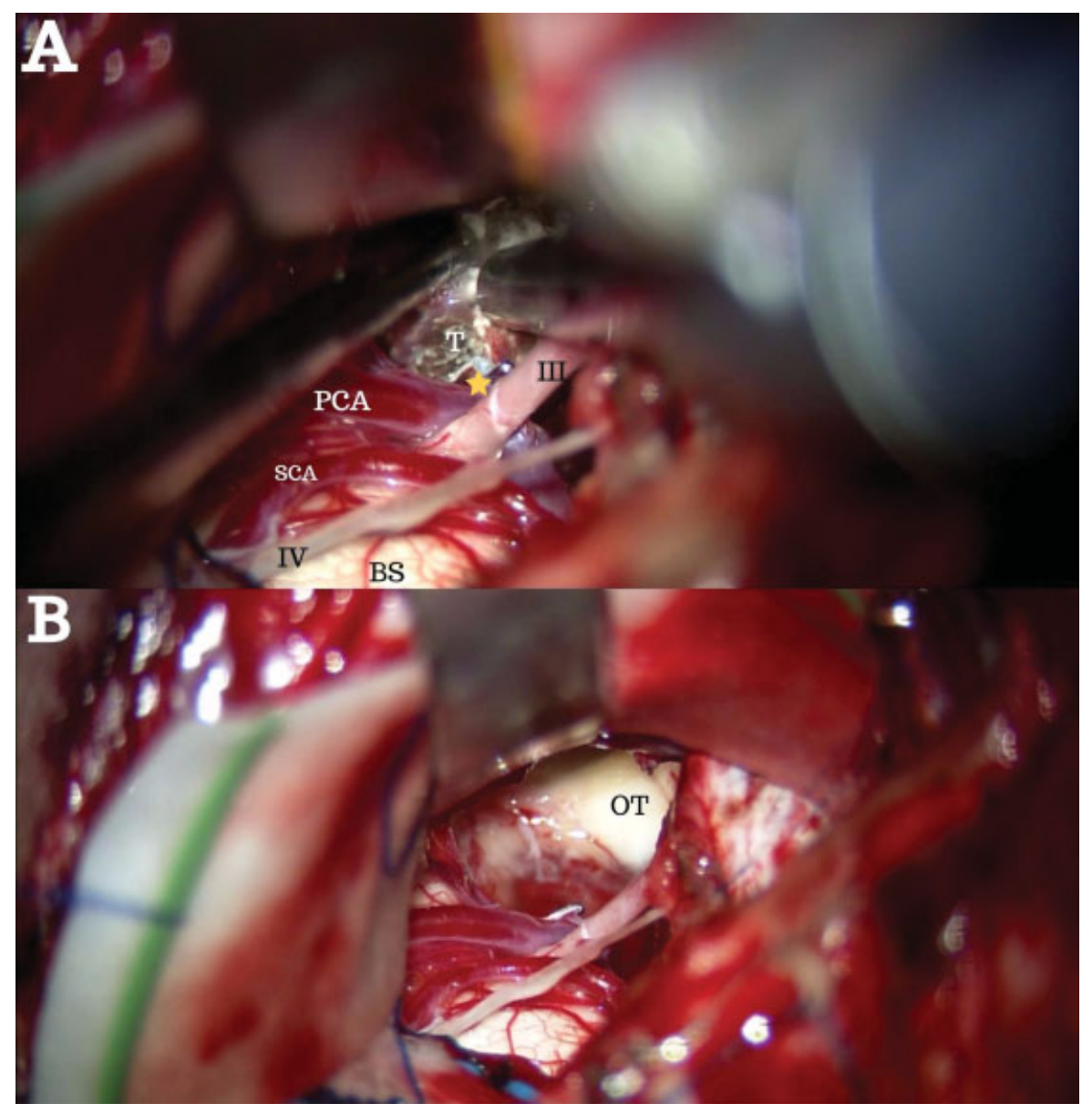

Fig. 2 Intraoperative images showing the retrochiasmatic area with tumor and vital neurovascular bundle around (A) and the tumor bed visualized after the complete tumor removal, showing the left optic tract (B). T, tumor, III, right oculomotor nerve; PCA, right posterior cerebral artery; SCA, right superior cerebellar artery; IV, right trochlear nerve; BS, brain stem; OT, left optic tract; *, clipped right hyploplastic PCoM.

\section{References}

1 Kunihiro N, Goto T, Ishibashi K, Ohata K. Surgical outcomes of the minimum anterior and posterior combined transpetrosal approach for resection of retrochiasmatic craniopharyngiomas with complicated conditions. J Neurosurg 2014;120(01):1-11

2 Morisako H, Goto T, Goto H, Bohoun CA, Tamrakar S, Ohata K. Aggressive surgery based on an anatomical subclassification of craniopharyngiomas. Neurosurg Focus 2016;41(06):E10
3 Oyama K, Prevedello DM, Ditzel Filho LF, et al. Anatomic comparison of the endonasal and transpetrosal approaches for interpeduncular fossa access. Neurosurg Focus 2014;37 (04):E12

4 Taussky P, Kalra R, Coppens J, Mohebali J, Jensen R, Couldwell WT. Endocrinological outcome after pituitary transposition (hypophysopexy) and adjuvant radiotherapy for tumors involving the cavernous sinus. J Neurosurg 2011;115(01):55-62 